\title{
TINGKAT KECEMASAN PADA IBU HAMIL DENGAN KEJADIAN PRE EKLAMPSIA DI SEBUAH RS PROVINSI LAMPUNG
}

\author{
Novita Rudiyanti*, Erike Raidartiwi* \\ *Dosen Jurusan Kebidanan Poltekkes Tanjungkarang \\ Email: rudiyantinovita@yahoo.com
}

\begin{abstract}
Menurut laporan World Health Organization (WHO) tahun 2014 Angka Kematian Ibu (AKI) di dunia yaitu 289.000 jiwa. Pada Preeklampsia ringan, gejala subjektif belum dijumpai, tetapi pada preeklampsia berat diikuti keluhan subjektif berupa sakit kepala terutama daerah frontalis, rasa nyeri di daerah epigastrium, gangguan mata, penglihatan menjadi kabur, mual muntah, gangguan pernafasan sampai sianosis, dan terjadi gangguan kesadaran. Masalah dalam penelitian ini adalah tingginya kejadian preeklampsia di Provinsi Lampung. Tujuan penelitian ini diketahuinya hubungan tingkat kecemasan ibu hamil dengan kejadian preeklampsia di RS Lampung. Rancangan penelitian ini menggunakan metode analitik korelasi dengan desain Cross Sectional. Populasi dalam penelitian ini adalah seluruh ibu hamil yang dirawat di rumah sakit pada bulan Januari-April 2017. Sampel penelitian ini menggunakan Kuota Sampling. Data yang diambil adalah data primer, alat pengumpulan data berupa kuisioner. Analisis data yang digunakan univariat dengan persentase, bivariat dengan Chi Square. Hasil penelitian didapatkan dari 15 responden ibu hamil yang cemas terdapat $13(86.7 \%)$ responden yang mengalami Preeklampsia, dan sebanyak $2(13.3 \%)$ orang yang tidak mengalami Preeklampsia. Hasil uji statistik diperoleh $P$ Value $=$ 0.005 dan $\mathrm{OR}=12.188(95 \%$ CI $2.186-67.945)$. Penelitian menyimpulkan ada hubungan tingkat kecemasan ibu hamil dengan kejadian preeklampsia. Peneliti menyarankan agar petugas kesehatan di Rumah Sakit dapat membuat ruangan terpisah bagi ibu hamil yang mengalami Preeklampsia, sehingga tidak mengganggu psikis (cemas) ibu hamil yang tidak mengalami Preeklampsia.
\end{abstract}

Kata Kunci: Tingkat Kecemasan, Preeklampsia

\section{LATAR BELAKANG}

Persoalan kesehatan ibu dan anak sampai saat ini masih merupakan persoalan yang krusial di banyak negara dunia, karena merupakan indikator peningkatan derajat kesehatan masyarakat suatu Negara. Persoalan kesehatan ibu dan anak dijadikan salah satu dari 17 komitmen pemimpin dunia termasuk Indonesia dalam Sustainable Development Goals (SDGs) (Sugihantono, 2015). Komitmen ini akan dicapai dengan menargetkan peningkatan derajat kesehatan ibu secara signifikan, hal ini terlihat pada tahun 2016 adanya penurunan angka kematian ibu (AKI) menjadi 267 per 100.000 kelahiran hidup (KH) (Fotarisman, 2015).

Salah satu upaya pelayanan Kesehatan Ibu dan Anak (KIA), diantaranya menyangkut pelayanan dan pemeliharaan ibu hamil, misalnya melalui
Program buku KIA serta kelas ibu dan balita. Program ini bertujuan untuk meningkatkan kualitas hidup perempuan sebagai sumber daya manusia, khususnya pada saat kehamilan dengan merencanakan kehamilan yang sehat dan direncanakan dengan baik. Pelayanan kesehatan pada ibu hamil tidak hanya tertuju pada pemeliharaan kesehatan fisik saja tetapi juga kesehatan psikologis ibu. Pada dasarnya, bahwa perubahan antara fisik dan psikologis tersebut saling berpengaruh. Salah satu faktor kesehatan psikologis ibu adalah kecemasan, dimana kejadian kecemasan ini umum terjadi pada ibu hamil (Resmani Asih, 2014).

Kecemasan (ansietas) adalah sebuah emosi dan pengalaman subjektif dari seseorang. Pengertian lain dari cemas adalah suatu keadaan yang membuat sesorang tidak nyaman dan terbagi dalam beberapa tingkatan. Jadi, cemas berkaitan 
dengan perasaan yang tidak pasti dan tidak berdaya. (Farida \& Yudi.H, 2010). Menurut Black \& Andreasen sebagaimana yang dikemukakan oleh Mary C. Townsend dalam buku yang berjudul Essentials of Psychiatric Mental Health Nursing (2014) Kecemasan, ketakutan, ketegangan dari kegelisahan dari antisipasi bahaya, sumber yang sebagian besar tidak diketahui atau tidak dikenal. Kecemasan dapat dianggap sebagai patologis ketika mengganggu fungsi sosial dan pekerjaan, pencapaian tujuan yang diinginkan, atau kenyamanan emosional.

Kecemasan ditandai dengan gejala fisik, seperti : kegelisahan, anggota tubuh bergetar, banyak berkeringat, sulit bernafas, jantung berdetak kencang, merasa lemas, panas dingin, mudah marah atau tersinggung. Gejala behavior seperti berperilaku menghindar dan terguncang, serta gejala kognitif seperti : khawatir tentang sesuatu, perasaan terganggu akan ketakutan terhadap sesuatu yang terjadi dimasa depan, keyakinan bahwa sesuatu yang menakutkan akan segera terjadi, ketakutan akan ketidakmampuan untuk mengatasi masalah, pikiran terasa bercampur aduk atau kebingungan, sulit berkonsentrasi. Berdasarkan gejala-gejala tersebut, kecemasan dikelompokkan menjadi kecemasan ringan, sedang, berat dan panik (Resmani Asih, 2014).

Kekhawatiran dan kecemasan pada ibu hamil apabila tidak ditangani dengan serius akan membawa dampak dan pengaruh terhadap fisik dan psikis, baik pada ibu maupun janin. Terdapat penelitian yang menghubungkan peningkatan risiko kelahiran prematur terhadap peningkatan skor kecemasan antara trimester kedua dan ketiga. Menurut Suririnah (2004) sebagaimana yang dikutip oleh Irma dalam Jurnalnya yang berjudul Hubungan Karakteristik Ibu Hamil Trimester III Dengan Kecemasan Dalam Menghadapi Persalinan, penelitian lain menunjukkan bahwa ibu hamil dengan kecemasan yang tinggi ketika hamil akan meningkatkan resiko hipertensi pada kehamilan. Resiko hipertensi dapat berupa terjadinya stroke, preeklamsi, bahkan kematian pada ibu dan janin (Irma, 2009).

Menurut Manuaba (2010), Preeklampsia adalah mulainya kenaikan berat badan diikuti edema kaki atau tangan, peningkatan tekanan darah, dan terakhir terjadi di proteinuria. Pada Preeklampsia ringan, gejala subjektif belum dijumpai, tetapi pada preeklampsia berat diikuti keluhan subjektif berupa sakit kepala terutama daerah frontalis, rasa nyeri di daerah epigastrium, gangguan mata, penglihatan menjadi kabur, mual muntah, gangguan pernafasan sampai sianosis, dan terjadi gangguan kesadaran.

Sampai saat ini preeklamsi merupakan salah satu penyebab langsung angka kematian ibu dan bayi. Menurut laporan World Health Organization (WHO) tahun 2014 Angka Kematian Ibu (AKI) di dunia yaitu 289.000 jiwa. Beberapa negara memiliki AKI cukup tinggi seperti Afrika Sub-Saharan 179.000 jiwa, Asia Selatan 69.000 jiwa, dan Asia Tenggara 16.000 jiwa. Angka kematian ibu di negara-negara Asia Tenggara yaitu Indonesia 190 per 100.000 kelahiran hidup, Vietnam 49 per 100.000 kelahiran hidup, Thailand 26 per 100.000 kelahiran hidup, Brunei 27 per 100.000 kelahiran hidup, dan Malaysia 29 per 100.000 kelahiran hidup (WHO, 2014).

Menurut Seksi Kesga Dinkes Provinsi Lampung (2014) di Provinsi Lampung tahun 2013, kematian ibu disebabkan oleh perdarahan sebanyak 47 kasus, preklamsi sebanyak 46 kasus, partus lama sebanyak 1 kasus, aborsi sebanyak 1 kasus, dan lain-lain sebanyak 54 kasus. Berdasarkan Data Statistik di RSAM Lampung menunjukkan bahwa pada tahun 2013 terdapat $481 \mathrm{ibu}$ yang mengalami preeklampsia. Berdasarkan hasil prasurvey di RSUD Dr. H. Abdul Moeloek pada tahun 2014 terdapat 337 kasus preeklampsia, tahun 2015 terdapat 350 dan pada periode bulan Januari-Oktober 2016 sebanyak 225 kasus preeklampsia. Dari perbandingan data tersebut, angka kejadian preeklampsia sempat mengalami penurunan pada tahun 2014 dan mengalami kenaikan kembali pada tahun 
2015. (Data Statistik RSAM Lampung ,2015).

\section{METODE}

Rancangan penelitian ini menggunakan metode analitik korelasi dengan desain cross sectional, yaitu suatu penelitian untuk mempelajari dinamika korelasi antara faktor-faktor resiko dengan efek, dengan cara pendekatan, observasi atau pengumpulan data sekaligus pada suatu saat (point time approach).

Populasi dalam penelitian ini adalah ibu hamil yang dirawat pada bulan Januari sampai bulan April 2017 dan terdapat sebanyak 534 ibu hamil. Teknik sampling adalah cara atau teknik-teknik tertentu yang digunakan dalam mengambil sampel penelitian sehingga sampel tersebut sedapat mungkin mewakili populasinya. Besar sampel yaitu 38 orang. Jenis sampling yang digunakan adalah Kuota Sampling.

Jenis data yang diambil dalam penelitian ini adalah data primer mengunakan ceklist dan data sekunder mengunakan rekam medik. Alat ukur penelitian ini menggunakan Kuisioner dan ceklist yang akan diisi data pasien.

Pengukuran tingkat kecemasan adalah wawancara dan observasi, angket terdiri atas 14 pertanyaan. Adapun cara penilaiannya menurut Hamilton, M (1959) sebagaimana yang dikemukakan oleh Mary. C. Townsend dalam buku Essential Of Psychiatric Mental Health Nursing. Jika hasil skor $<14$ Tidak ada ansietas atau kecemasan. skor 14-17 ansietas ringan, skor 18-24 ansietas sedang dan skor 25-30 ansietas berat. Sedangkan preeklamsia teknik pengukurannya menggunakan diagnosa dokter yang tertulis didalam rekam medik.

Analisis univariat menggunakan distribusi frekuensi dan persentase. Sedangkan analisis bivariat dengan mengunakan uji statistik Chi Square dengan tingkat kepercayaan 95\%, $(\alpha=$ $0,05)$. Analisis bivariat dilakukan untuk menguji hubungan antara variabel dependen dan variabel independen yaitu dengan menggunakan uji chi square.

\section{HASIL}

\section{Analisis Univariat}

Hasil penelitian disajikan melalui analisis univariat dan bivariat dengan uji chi square.

Tabel 1: Distribusi Frekuensi Karakteristik Ibu Hamil

\begin{tabular}{llcc}
\hline \multicolumn{2}{l}{ Karakteristik Ibu Hamil } & f & $\%$ \\
\hline \multirow{2}{*}{$\begin{array}{l}\text { Umur } \\
\text { responden }\end{array}$} & 35 atau $>$ & 7 & 18.4 \\
& $20-35$ & 31 & 81.6 \\
\hline \multirow{3}{*}{ Jumlah } & Primigravid & & \\
Kehamilan & a & 13 & 34.2 \\
& Multigravid & 25 & 65.8 \\
& a & & \\
\hline \multirow{3}{*}{ Pendidikan } & SD & 5 & 13.2 \\
Terakhir & SMP & 19 & 50.0 \\
& SMA & 11 & 28.9 \\
& PT & 3 & 7.9 \\
\hline Pekerjaan & IRT & 36 & 94.7 \\
Responden & Lain-lain & 2 & 5.3 \\
\hline
\end{tabular}

Berdasarkan tabel di atas dapat dilihat bahwa dari 38 responden, sebanyak 31 (81.6\%)orang berumur 20-35 tahun. Untuk jumlah kehamilan mayoritas responden yaitu sebanyak 25 (65.8\%)orang adalah Ibu Multigravida (kehamilan lebih dari satu). Sedangkan, jika dilihat dari segi pendidikan, tingkat pendidikan terbanyak adalah responden dengan pendidikan terakhir SMP sebanyak 19 (50.0\%)orang dan pendidikan terakhir yang paling sedikit sebanyak 3 (7.9\%)orang dengan pendidikan terakhir Perguruan Tinggi. Namun, jika dilihat dari pekerjaannya responden mayoritas bekerja sebagai Ibu Rumah Tangga sebanyak 36 (94.7\%)orang. 
Tabel 2: Distribusi Frekuensi Ibu Hamil yang Mengalami Preeklampsia

\begin{tabular}{lcc}
\hline \multicolumn{1}{c}{ Pre Eklamsia } & f & $\%$ \\
\hline Pre eklampsia & 21 & 55,3 \\
\hline Tidak pre eklamsia & 17 & 44,7 \\
\hline Jumlah & 38 & 100 \\
\hline
\end{tabular}

Berdasarkan data pada tabel di atas dapat dilihat bahwa dari 38 orang responden yang mengalami Preeklampsia sebanyak $21(55.3 \%)$ responden

Tabel 3: Distribusi Frekuensi Tingkat Kecemasan Ibu Hamil

\begin{tabular}{lcc}
\hline Kecemasan & $\mathrm{f}$ & $\%$ \\
\hline Cemas & 15 & 39.5 \\
\hline Tidak Cemas & 23 & 60.5 \\
\hline Jumlah & 38 & 100 \\
\hline
\end{tabular}

Berdasarkan data pada tabel 3 dari 38 orang responden didapatkan hasil sebanyak $15 \quad(39.5 \%)$ responden mengalami cemas.

Tabel 4: Hubungan Tingkat Kecemasan Ibu Hamil dengan Kejadian Preeklampsia

\begin{tabular}{lcccccc}
\hline \multirow{2}{*}{$\begin{array}{c}\text { Tingkat } \\
\text { Kecemasan }\end{array}$} & \multicolumn{3}{c}{ Pre Eklampsia } & \multicolumn{2}{c}{ Total } \\
\cline { 2 - 6 } & $\begin{array}{c}\text { Pre } \\
\text { Eklampsia }\end{array}$ & \multicolumn{2}{c}{ Tidak Pre } \\
& Eklampsia & $\mathrm{f}$ & $\%$ \\
\cline { 2 - 6 } Cemas & 13 & 86.7 & 2 & 13.3 & 15 & 100 \\
\hline Tidak Cemas & 8 & 34.8 & 15 & 65.2 & 23 & 100 \\
\hline Total & 21 & 55.3 & 17 & 44.7 & 38 & 100 \\
\hline p value & \multicolumn{5}{c}{0,005} \\
\hline OR 95\% CI & \multicolumn{6}{c}{$12,188(2.186-67.945)$} \\
\hline
\end{tabular}

Hasil analisis hubungan tingkat kecemasan ibu hamil dengan kejadian preeklampsia diperoleh bahwa dari 15 responden ibu hamil yang cemas terdapat 13 responden yang mengalami Preeklampsia, dan sebanyak 2 (13.3\%)orang yang tidak mengalami preeklampsia.

Hasil uji statistik mengguvakan uji Chi Square diperoleh nilai $p$ value $=0.005$ yang berarti $p<0.05$. Sehingga, secara statistik dapat disimpulkan ada hubungan yang signifikan antara tingkat kecemasan ibu hamil dengan kejadian preeklampsia pada ibu hamil di RSUD Dr. H. Abdul Moeloek Provinsi Lampung tahun 2017. Sedangkan odd rasio/faktor resiko (OR) yaitu 12.188 (2.186-67.945) sehingga responden dengan perasaan Cemas beresiko 12 kali lebih besar mengalami Preeklampsia dibanding yang tidak cemas.

\section{PEMBAHASAN}

\section{Pre Eklampsia}

Berdasarkan tabel distribusi frekuensi kejadian preeklampsia pada ibu hamil $21(55.3 \%)$ orang dan yang tidak preeklampsia 17 (44.7\%) di RSUD Dr. H. Abdul Moeloek Provinsi Lampung tahun 2017.

Hal ini sejalan dengan teori Manuaba (2010) Preeklamsia adalah mulainya kenaikan berat badan diikuti edema kaki atau tangan, peningkatan tekanan darah , dan terakhir terjadi di proteinuria. Pada Preeklampsi ringan, gejala subjektif belum dijumpai, tetapi pada preeklampsi berat diikuti keluhan subjektif berupa sakit kepala terutama daerah frontalis, rasa nyeri di daerah epigastrium, gangguan mata, penglihatan menjadi kabur, mual muntah, gangguan pernafasan sampai sianosis, dan terjadi gangguan kesadaran.

Oleh karena itu, menurut peneliti Preeklampsia dapat terjadi pada setiap ibu hamil dengan sebab yang belum jelas dengan tiga gejala utama yaitu hipertensi, oedema, proteinuria. Jika dikaitkan dengan karakteristik responden berdasarkan pendidikan terakhir mayoritas responden memiliki pendidikan SMP, sehingga pengetahuan yang ibu miliki kurang dan mengakibatkan ibu tidak menyadari lebih awal bahwa dirinya mengalami Preeklampsia.

Tingginya kasus preeklampsia dalam penelitian ini juga dipengaruhi oleh status RSUD Dr. H. Abdul Moeloek Provinsi Lampung yang merupakan rumah sakit rujukan tertinggi yang ada di Provinsi Lampung. Untuk itu diperlukan peengetahuan yang baik agar ibu hamil dapat mengetahui gejala preeklampsia, 
sehingg aibu hamil dapat segera mencari pertolongan bila merasakan gejala preeklampsia. Diharapkan seiring bertambahnya pengetahuan yang dimiliki oleh ibu, ibu akan memeriksakan kehamilannya lebih teratur sesuai standar pemeriksaan ANC (minimal 4x selama kehamilan) agar resiko terjadinya preeklampsia dapat terdeteksi sedini mungkin dan dapat dilakukan penanganan segera.

\section{Tingkat Kecemasan}

Berdasarkan hasil penelitian dari 38 responden ibu hamil di Ruang Delima RSUD Dr. H. Abdul Moeloek tahun 2017 sekitar $15(39.5 \%)$ orang ibu hamil yang mengalami cemas. Hal ini sejalan dengan Aprinawati (2010) sebagai mana dikutip oleh Wa Ode Sitti Nurbaedah dalam KTInya yang berjudul "Gambaran Tingkat Kecemasan Ibu Hamil Trimester II Dalam Menghadapi Persalinan di Wilayah Kerja Puskesmas Katobu Tahun 2016" bahwa kecemasan adalah perasaan yang tidak jelas tentang keprihatinan dan khawatir karena ancaman pada sistem nilai atau pola keamanan seseorang. Individu mungkin dapat mengidentifikasikan situasi misalnya persalinan, tetapi pada kenyataannya ancaman terhadap diri berkaitan dengan khawatir dan keprihatinan yang terlibat di dalam situasi. Situasi tersebut adalah sumber dari ancaman, tetapi bukan ancaman itu sendiri.

Berdasarkan hasil yang didapat dari penelitian yang dilakukan oleh Wa Ode Sitti Nurbaedah di Wilayah Kerja Puskesmas Katobu Tahun 2016 dari 56 responden terdapat sebanyak 26 responden (46,43\%) yang mengalami cemas. Menurut peneliti ibu hamil yang mengalami Kecemasan disebabkan oleh banyak faktor yaitu umur yang terlalu muda atau terlalu tua, tingkat pendidikan yang rendah, paritas, dan pekerjaan. Umur yang terlalu muda dapat mengakibatkan belum matangnya keadaan psikologis ibu. Umur yang terlalu tua dapat mengakibatkan ibu merasa cemas karna ibu merasa kemampuan dan tenaga ibu untuk melahirkan berkurang. Ibu dengan paritas
Multipara (kelahiran lebih dari satu kali) memiliki lebih banyak resiko yang akan dialaminya salah satunya ialah mengalami kecemasan akibat dari permasalahan terhadap kelahiran yang terjadi sebelumnya seperti seorang wanita yang pernah mengalami masalah dalam mendapatkan keturunan akan menjadi sangat cemas mengenai apakah mereka akan mampu mempertahankan kehamilannya kali ini.

Wanita yang mengalami keguguran akan terus menerus ketakutan sampai usia kehamilannya melewati tanggal dimana sebelumnya mereka kehilangan bayi serta wanita yang pernah melahirkan seorang bayi yang kemudian meninggal atau mengalami kelainan. Namun, bebrapa wanita lainnya tetap tenang dan percaya diri (Nolan,2003).

\section{Hubungan Tingkat Kecemasan dengan Kejadian Preeklampsia}

Dari hasil penelitian diketahui tingkat kecemasan responden dalam kehamilan yang paling tinggi ialah responden yang mengalami kecemasan berat dan mengalami preeklampsia sebanyak 13 (86.7\%) orang. Hasil tersebut didapatkan karena responden kurang mendapatkan informasi yang cukup dari sumber yang memberikan informasi secara langsung, selain itu juga dari latar pendidikan yang paling banyak ialah SMP. Semakin tinggi tingkat pendidikan akan semakin baik tingkat pengetahuannya, sehingga memungkinkan responden untuk menerima informasi yang diberikan. Selain dari latar pendidikan yang kurang, responden yang kehamilannya Multivariat atau kehamilan yang lebih dari satu kali juga dapat mempengaruhi tingkat kecemasan responden.

Hasil ini sejalan dengan penelitian yang dilakukan oleh Wulan Rizky,dkk dengan penelitian yang berjudul "Hubungan Pola Makan dan Stress dengan Kejadian Hipertensi Grade 1 dan 2 Pada Ibu Hamil di Wilayah Kerja Puskesmas Kamonji Kecamatan Palu Barat" dari penelitian ini menunjukan bahwa terdapat hubungan antara stress dengan kejadian 
hipertensi pada ibu hamil dengan $P$ Value $0.000<0.05$.

Berdasarkan hasil yang didapat oleh peneliti, didapatkan hasil yang sejalan dengan penelitian yang dilakukan oleh Adi Isworo,dkk dengan penelitian yang berjudul "Hubungan antara Kecemasan dengan Kejadian Preeklampsia Di Kabupaten Banyumas Jawa Tengah" dari penelitian ini didapatkan hasil analisis bivariat antara kecemasan dengan kejadian preeklampsia pada ibu hamil yang didapatkan hasil $\mathrm{OR}=7,84 ; \quad(\mathrm{CI}=3,967-$ 15.501); $\mathrm{p}=0,00$. Interpretasinya adalah kejadian preeklampsia pada ibu hamil akan meningkat 7,84 kali pada ibu yang mengalami kecemasan dibandingkan dengan ibu yang tidak mengalami kecemasan, dan secara statistik bermakna dengan nilai $\mathrm{p}=0,00$.

Kecemasan (ansietas) adalah sebuah emosi dan pengalaman subjektif dari seseorang. Pengertian lain dari cemas adalah suatu keadaan yang membuat sesorang tidak nyaman dan terbagi dalam beberapa tingkatan. Jadi, cemas berkaitan dengan perasaan yang tidak pasti dan tidak berdaya. (Farida dan Yudi.H, 2010). Menurut Black \& Andresen sebagaimana yang dikemukakan oleh Mary C. Townsend dalam bukunya yang berjudul Essentials of Psychiatric Mental Health Nursing bahwa kecemasan, ketakutan, ketegangan dari kegelisahan dari antisipasi bahaya, sumber yang sebagian besar tidak diketahui atau tidak dikenal. Kecemasan dapat dianggap sebagai patologis ketika mengganggu fungsi sosial dan pekerjaan, pencapaian tujuan yang diinginkan, atau kenyamanan emosional.

Mengingat kecemasan ini timbul karena rasa takut yang berlebihan atau trauma, peran keluarga saat ibu sedang hamil sangatlah penting. Diharapkan kepada keluarga untuk dapat berperan serta untuk mengurangi kecemasan ibu hamil dengan cara menemani ibu dalam melakukan pemeriksaan ANC, memberikan ibu dudkungan moril dan terus memotivasi ibu sehingga ibu merasa lebih percaya diri dan tenang dalam menghadapi kehamilan dan persalinan

\section{KESIMPULAN}

Penelitian ini menyimpulkan bahwa ada pengaruh pijat oksitosin terhadap involusi uterus ibu postpartum dapat diuraikan sebagai berikut: Involusi uterus pada ibu postpartum yang diberikan pijat oksitosin memiliki rerata 3,19 jari di bawah pusat. Involusi uterus pada ibu postpartum yang tidak diberikan pijat oksitosin memiliki rerata 1,75 jari di bawah pusat. Ada pengaruh pijat oksitosin dengan proses involusi uterus pada ibu postpartum. Dengan $p$ value $0,000<0,05$.

Selanjutnya penulis menyarankan kepada tenaga kesehatan khususnya kepada tenaga kesehatan yang bekerja di fasilitas kesehatan yang memberikan pelayanan postnatal, untuk memberikan pijat oksitosin kepada ibu postpartum sebagai salah satu alternatif upaya dan inovasi baru dalam mengurangi angka kematian ibu yang disebabkan oleh perdarahan postpartum

\section{DAFTAR PUSTAKA}

Adi Isworo, dkk. 2012. Hubungan antara Kecemasan dengan Kejadian Preeklampsia di Kabupaten Banyumas Jawa Tengah. (https://journal.ugm.ac.id) [11 Juli 2017]

Fotarisman. 2015. SDGS dan Kematian Ibu di Indonesia. Tersedia. http://transformativeanalysis.blogspo t.co.id) [10 Desember 2016]

Irma. 2009 Hubungan Karakteristik Ibu Hamil Trimester III dengan Kecemasan dalam Menghadapi Persalinan. Tersedia. (Journals.unpad.ac.id) [10 Desember 2016]

Kusumawati Farida; Hartono Yudi. 2011. Buku Ajar Keperawatan Jiwa. Jakarta: Salemba Medika. 152 Halaman

Manuaba, I.B.G. 2007 Pengantar Kuliah Obstetri. Jakarta: Buku Kedokteran

Resmaniasih 2014 (http://eprints.uny.ac.id) [04 Januari 2017] 
Risky Wulan Ramadani Taslim.Rina Kundre.Gresty Masi Hubungan Pola Makan Dan Stres Dengan Kejadian Hipertensi Grade 1 Dan 2 Pada Ibu Hamil Di Wilayah Kerja Puskesmas Kamonji Kecamatan Palu Barat Tersedia. (https://ejournal.unsrat. ac.id ) [29 Mei 2017]

Sugihantono.2015. Strategi Peningkatan Kesehatan dengan SDG'S. Tersedia (http://www.scribd.com)

Desember 2016]

Townsend, Mary C. 2014. Essentials of Psychiatric Mental Health Nursing. United State of America: F. A. Davis Company

Nurbaedah Wa Ode Sitti.2016. Gambaran Tingkat Kecemasan Ibu Hamil Trimester II Dalam Menghadapi Persalinan di Wilayah Kerja Puskesmas Katobu. Tersedia 